\title{
The effects of single high-dose or daily low- dosage oral colecalciferol treatment on vitamin D levels and muscle strength in postmenopausal women
}

Mahmut Apaydin ${ }^{1 *}$ D, Asli Gencay Can², Muhammed Kizilgul', Selvihan Beysel', Seyfullah Kan ${ }^{1}$, Mustafa Caliskan', Taner Demirci ${ }^{1}$, Ozgur Ozcelik', Mustafa Ozbek ${ }^{1}$ and Erman Cakal ${ }^{1}$

\begin{abstract}
Introduction: Vitamin D deficiency is a common health problem. Vitamin D supplements are used to improve vitamin D status; however, there are contradictory data related to what doses to give and how often they should be given. Many studies have investigated the effects of vitamin D supplementation on muscle strength, but the results remain controversial. We aimed to compare the effects and safety of single high-dose with daily low-dose oral colecalciferol on 25(OH)D levels and muscle strength in postmenopausal women with vitamin D deficiency or insufficiency.

Methods and design: Sixty healthy postmenopausal women who had serum vitamin D levels $<20 \mathrm{ng} / \mathrm{mL}$ $(50 \mathrm{nmol} / \mathrm{L})$ were enrolled in the study. Group $1(n=32)$ was given daily oral dosages of $800 \mathrm{IU}$ vitamin D3, and group $2(n=28)$ was given a single oral dose of 300,000 IU vitamin D3. Serum vitamin D levels and muscle strengths were measured at the beginning, 4 th, and 12th week. Muscle strength tests were performed at $60^{\circ}$ using a Biodex system 3 isokinetic dynamometer.

Results: Pretreatment vitamin D levels did not differ between the two groups $(10.2 \pm 4.4 \mathrm{ng} / \mathrm{mL}(25,4 \pm 10,9$ $\mathrm{nmol} / \mathrm{L}) ; 9.7 \pm 4.4 \mathrm{ng} / \mathrm{mL}(24,2 \pm 10,9 \mathrm{nmol} / \mathrm{L}), p>0.05)$. A significant increase in vitamin $D$ levels was observed in both groups at 4 and 12 weeks after vitamin D3 treatment. The increase in the single-dose group was significantly higher than the daily low-dosage group at the 4 th week $(35.9 \pm 9.6 \mathrm{ng} / \mathrm{mL}(89,6 \pm 23,9 \mathrm{nmol} / \mathrm{L}), 16.9 \pm 5.8 \mathrm{ng} / \mathrm{mL}$ $(42,1 \pm 14,4 \mathrm{nmol} / \mathrm{L}), p=0.01)$. The increase in the single-dose group was significantly higher than in the daily low dosage group at the 12 th week $(23.4 \pm 4.7 \mathrm{ng} / \mathrm{mL}(58,4 \pm 11,7 \mathrm{nmol} / \mathrm{L}), 19.8 \pm 7.2 \mathrm{ng} / \mathrm{mL}(49,4 \pm 17,9 \mathrm{nmol} / \mathrm{L})$, $p=0.049$ ). The quadriceps muscle strength score increased significantly in the daily group at the 4 th week $(p=0.038)$. The hamstring muscle strength score increased significantly in the daily group at the 12th week $(p=0.037)$.
\end{abstract}

Conclusion: Although daily administration routes are more effective in improving muscle strength, a single administration is more effective in increasing vitamin D levels.

Trial registration number: ISRCTN14226530 (04.07.2018), Name of the registry: ISRCTN registry, The study was retrospectively registered.

Keywords: Vitamin D, Muscle strength, Postmenopausal women

\footnotetext{
* Correspondence: drmahmutapaydin@gmail.com

'Department of Endocrinology and Metabolism, Diskapi Training and

Research Hospital, Ankara, Turkey

Full list of author information is available at the end of the article
}

(c) The Author(s). 2018 Open Access This article is distributed under the terms of the Creative Commons Attribution 4.0 International License (http://creativecommons.org/licenses/by/4.0/), which permits unrestricted use, distribution, and reproduction in any medium, provided you give appropriate credit to the original author(s) and the source, provide a link to the Creative Commons license, and indicate if changes were made. The Creative Commons Public Domain Dedication waiver (http://creativecommons.org/publicdomain/zero/1.0/) applies to the data made available in this article, unless otherwise stated. 


\section{Background}

Vitamin D is a fat-soluble vitamin that is now known to play an important role in a variety of biologic functions including immune regulation, proliferation, differentiation, apoptosis, and angiogenesis, in addition to being the main hormone regulating calcium phosphate homeostasis and mineral bone metabolism [1]. Vitamin $\mathrm{D}$ deficiency is often undiagnosed and untreated because it has insidious or nonspecific signs and symptoms, and is a common health problem worldwide [2]. Many authors agree that a 25-hydroxyvitamin D3 (25(OH)D3) concentration less than $20 \mathrm{ng} / \mathrm{mL}(50 \mathrm{nmol} / \mathrm{L})$ is defined as vitamin D deficiency; however, a $25(\mathrm{OH}) \mathrm{D} 3$ concentration between 21 and $29 \mathrm{ng} / \mathrm{mL}(50-74 \mathrm{nmol} / \mathrm{L})$ is defined as vitamin D insufficiency [3]. The form of vitamin $\mathrm{D}$ therapy, the dose and dosing interval, and route of administration are not given much importance because there are no specific recommendations or guidelines in this regard [4]. It is well documented that increasing $25(\mathrm{OH}) \mathrm{D} 3$ serum levels in patients with vitamin D deficiency increases intestinal calcium absorption, decreases parathyroid hormone (PTH) levels, fall incidence and fracture risk, and increases muscle strength [5]. Serum $25(\mathrm{OH}) \mathrm{D} 3$ is accepted as the best indicator of vitamin D condition [6]. The cell nuclei of muscle cells express the vitamin D receptor (VDR) [7] and vitamin D has an impact on muscle cell contractility [8]. Vitamin D deficiency leads to disruption in muscular protein synthesis and consequently muscle mass, and finally muscle strength decreases as a result [9]. Vitamin D deficiency may lead to myopathy. Vitamin D supplementation is considered to have an influence on muscle fiber composition and morphology in vitamin $\mathrm{D}$ deficient older adults [10].

In a study conducted in 167 postmenopausal women, it was demonstrated that a serum 25(OH)D3 level higher than $20 \mathrm{ng} / \mathrm{mL}(50 \mathrm{nmol} / \mathrm{L})$ was achieved with a vitamin $\mathrm{D}$ (3) dosage of $800 \mathrm{IU} / \mathrm{d}$ in $97.5 \%$ of women [11]. It is known that daily vitamin $\mathrm{D}$ supplementation reduces the frequency of falls and fractures in older women [12]. However, poor adherence to oral vitamin D replacement is a common clinical problem $[13,14]$. Several studies about the pharmacokinetics, biochemical effects, efficacy, and safety proved that a single large dose of colecalciferol was safe, well tolerated, and effective [15-19]. In a systematic review of studies using large, single-dose, oral vitamin D supplementation in adult populations, a single vitamin D3 dose of $\geq 100,000$ IU was shown to provide a perdurable effective means of increasing short-term vitamin $\mathrm{D}$ concentrations to $>20 \mathrm{ng} / \mathrm{mL}(50 \mathrm{nmol} / \mathrm{L})$. However, larger vitamin D3 doses of $\geq 300,000$ IU were required to achieve 25(OH)D3 concentrations $>30 \mathrm{ng} / \mathrm{mL}$ (75 nmol/L) and decreased plasma PTH concentrations [20]. Despite the presence of many studies on this topic, an accepted recommendation about the best dose and dose interval is still lacking.

Many studies have investigated the effects of vitamin D supplementation on muscle function but the results remain controversial. Some studies observed a favorable effect of vitamin D supplementation on muscle strength $[21,22]$, whereas others failed to show this beneficial effect $[16,23,24]$. A meta-analysis demonstrated that muscle strength could be improved by vitamin D supplementation [25]. On the contrary, another meta-analysis including 12 studies, which focused on older subjects with baseline $25(\mathrm{OH}) \mathrm{D} 3$ concentrations higher than (10 ng/mL) $25 \mathrm{nmol} / \mathrm{L}$, indicated no beneficial effect of vitamin D supplementation on muscle strength [26].

The primary aim of this study was to evaluate and compare the effects and safety of single high- dose with daily low-dosage oral colecalciferol on 25(OH)D3 levels in older patients with vitamin $\mathrm{D}$ deficiency or insufficiency.

\section{Methods}

We enrolled 60 healthy, postmenopausal women aged 50-68 years whose vitamin D level was lower than $20 \mathrm{ng} / \mathrm{mL}(50 \mathrm{nmol} / \mathrm{L})$. The participants, who were followed up by our clinic in Diskapi Training and Research Hospital, were consecutively randomized to the administration of daily $800 \mathrm{IU}(n=32)$ or a single oral bolus of 300,000 IU $(n=28)$ of vitamin $\mathrm{D}_{3}$. Individuals who had granulomatous conditions, thyroid disease, malabsorption syndromes, liver disease, kidney disease, diabetes or postural instability (cerebellar disease, vestibular disease, vitamin B12 deficiency, drugs), and individuals taking anticonvulsants, calcium or vitamin D supplements, barbiturates, or steroids in any form were excluded. The study protocol was approved by the medical ethics committee of the Ankara Diskapi Training and Research Hospital, and all subjects gave written informed consent.

\section{Design overview}

Our study was a randomized clinical trial that lasted 3 months. The participants were collected in the spring and winter of 2015-2016 to minimize seasonal effects. Serum vitamin D levels and muscle strengths were measured at the beginning, and 4th and 12th weeks of treatment. The physiotherapist who assessed all functional endpoints was blinded to both regimens and the physiotherapist who performed the assessments was blinded to the treatment groups.

\section{Analytical methods}

Calcium and phosphate were measured using an enzyme method with an autoanalyzer (ADVIA 2400, Siemens Healthcare Diagnostics Inc., Tarrytown, NY, USA). iPTH 
and $25(\mathrm{OH}) \mathrm{D}$ were measured using an immunochemiluminescent assay (Siemens Advia Centaur XP, Siemens Healthcare Diagnostics Inc., Tarrytown, NY, USA).

Quadriceps (knee extensors) and hamstring (knee flexors) muscle strengths of each leg were measured in Biodex System 3 isokinetic dynamometer (Biodex, Shirley, NY) at the beginning, and 4th and 12th weeks of treatment. The patients were strapped into the chair with their knee flexed at $90^{\circ}$. The anatomic axis of the knee (lateral femoral condyle) was aligned with the axis of the dynamometer. The resistance pad was placed proximal to the medial malleolus. A seat belt harness was placed around the patient's chest and thigh for stabilization. The range of motion varied from $90^{\circ}$ knee flexion to full extension. Maximal quadriceps and hamstring peak torques $(\mathrm{Nm})$ were obtained through concentric isokinetic knee extension and flexion performed at the angular velocity of $60^{\circ} / \mathrm{sn}$ for 5 consecutive contractions. The highest peak torque value of these 5 contractions was recorded. The value of peak torque for each muscle was divided by body weight and the relative peak value $(\mathrm{Nm} / \mathrm{kg})$ was calculated. Isokinetic muscle strength was assessed using the relative peak value. All patients indicated that their right leg was dominant.

\section{Statistical analysis}

Statistical analysis was performed using the SPSS 18.0 (SPSS, Inc) software. Descriptive analyses are expressed as the mean \pm standard deviation (SD) and percentages (\%). Normality was tested using the Kolmogorov-Smirnov and Shapiro-Wilk W tests. The Chi-square test or Fisher's exact test, where appropriate, were used to compare categorical variables. Student's t-test was used for normally distributed continuous variables. The Mann-Whitney $U$ test was used for continuous variables that were not normally distributed. The paired samples t-test was used for normally distributed continuous variables. $p<0.05$ was considered as statistically significant.

\section{Results}

The clinical characteristics of study subjects are summarized in Table 1 . There was no significant difference between the daily dosage and single-dose group according to age, body weight, height, and body mass index (BMI) $(p>0.05)$. There was no significant difference between the two groups in terms of sun exposure, physical activity, milk consumption, smoking habits, and clothing style $(p>0.05)$.

There was no difference in serum glucose, total cholesterol, low-density lipoprotein (LDL)-cholesterol, triglycerides, high-sensitivity C-reactive protein (hs-CRP) and thyroid-stimulating hormone (TSH) levels between the single-dose and daily-dosage groups at pretreatment,
4 th, and 12th week $(p>0.05)$. Serum calcium and alkaline phosphatase and PTH levels were not different between the single-dose and daily-dosage groups at pretreatment, 4th, and 12th week ( $\mathrm{p}>0.05)$. The single-dose $(9.7 \pm 4.4 ; 35.9 \pm 9.6$ and $23.1 \pm 4.7 \mathrm{ng} / \mathrm{mL}(24.2 \pm 10.9$; $89.6 \pm 23.9$ and $57.6 \pm 11.7 \mathrm{nmol} / \mathrm{L}), p<0.001)$ and daily-dosage groups $(10.2 \pm 4.4,16.9 \pm 5.8$, and $19.8 \pm 7.2 \mathrm{ng} /$ $\mathrm{mL}(25.4 \pm 10.9 ; 42.1 \pm 14.4$ and $49.4 \pm 17.9 \mathrm{nmol} / \mathrm{L}), p$ $<0.001$ ) had lower pretreatment vitamin D levels than in the 4th and 12th week, respectively. Pretreatment vitamin $\mathrm{D}$ levels did not differ between the groups $(p>0.05)$. The vitamin D level was higher in the single-dose group than in the daily-dosage group at the 4th $(p=0.001)$ and 12th week $(p=0.49)$. The daily-dose group had lower pretreatment phosphorus levels than in 4th and 12th week $(p<0.001)$, whereas the single-dose group had higher phosphorus levels at the 4th week than at pretreatment and the 12th week $(p=0.043)$. Phosphorus levels were not different between two groups at pretreatment, 4th, and 12th week $(p>0.05)$. Pretreatment magnesium levels were not different between the two groups $(p>0.05)$. The pretreatment osteocalcin level was higher in the single-dose group than in the daily-dosage group $(p=0.022)$. The osteocalcin level was not different between the two groups at the 4th and 12th week $(p>0.05)$. The biochemical results of the single-dose and daily-dosage group at pretreatment, 4th, and 12th week are shown in Table 2.

The relative isokinetic peak values for knee extensor and flexor (both dominant and non-dominant) muscles did not differ between pretreatment, 4th, and 12th week in the single-dose group $(p>0.05)$. The pretreatment peak values for dominant knee extensors were lower as compared with the 4th week in the daily-dosage group $(0.97 \pm 0.4$ vs. $1.06 \pm 0.4 \mathrm{~N} / \mathrm{m} / \mathrm{kg}$, respectively, $p=0.03)$. Pretreatment peak values for non-dominant knee flexors were lower as compared with the 12th week in daily-dosage group $(0.32 \pm 0.1$ vs. $0.37 \pm 0.1 \mathrm{Nm} / \mathrm{kg}$, respectively, $\mathrm{p}=0.03)$. The daily-dosage group had similar dominant knee flexors and non-dominant knee extensors between pretreatment, 4th, and 12th week $(p>0.05)$. The relative peak values for knee extensor and flexor (both dominant and non-dominant) muscles did not differ between the daily- dosage and single-dose group according to pretreatment, 4th, and 12th week $(p>0.05)$. The relative isokinetic peak values of the dominant and non-dominant knee extensor and flexor muscles are shown in Table 3 . Muscle function tests measured at 1st month in daily dose group were similar between patients who achieved $25 \mathrm{OHVitD}_{3}$ level of $>20 \mathrm{ng} / \mathrm{mL}(50 \mathrm{nmol} / \mathrm{L})$ and patients with lower than $20 \mathrm{ng} / \mathrm{mL}(50 \mathrm{nmol} / \mathrm{L})$.

All patients in both groups had baseline vitamin $\mathrm{D}$ levels lower than $20 \mathrm{ng} / \mathrm{mL} \quad(50 \mathrm{nmol} / \mathrm{L})$. Serum 
Table 1 The clinical characteristics of the daily dosage group and the single-dose group

\begin{tabular}{|c|c|c|c|}
\hline & Daily dosage group $(n=32)$ & Single-dose group $(n=28)$ & $p$ value \\
\hline \multicolumn{4}{|l|}{ Characteristics (mean \pm SD) } \\
\hline Age (years) & $51.60 \pm 5.80$ & $51.58 \pm 5.54$ & 0.644 \\
\hline Height (cm) & $160.40 \pm 7.94$ & $158.75 \pm 5.10$ & 0.152 \\
\hline Body weight, pretreatment (kg) & $76.51 \pm 12.51$ & $72.04 \pm 12.34$ & 0.115 \\
\hline BMI, pretreatment $\left(\mathrm{kg} / \mathrm{m}^{2}\right)$ & $29.75 \pm 5.31$ & $28.61 \pm 4.96$ & 0.354 \\
\hline Body weight, 12th week, (kg) & $74.51 \pm 12.51$ & $72.48 \pm 12.84$ & 0.544 \\
\hline BMI, 12th week, $\left(\mathrm{kg} / \mathrm{m}^{2}\right)$ & $29.07 \pm 5.34$ & $28.8 \pm 5.24$ & 0.855 \\
\hline Sun exposure (\%) & & & 0.255 \\
\hline$<1 \mathrm{~h} / \mathrm{d}$ & 0 & 3.6 & \\
\hline $1-2 \mathrm{~h} / \mathrm{d}$ & 15.6 & 17.9 & \\
\hline $2-4 \mathrm{~h} / \mathrm{d}$ & 56.3 & 39.3 & \\
\hline $4-7 \mathrm{~h} / \mathrm{d}$ & 21.9 & 38.5 & \\
\hline$>7 \mathrm{~h} / \mathrm{d}$ & 6.3 & 0 & \\
\hline Physical activity (\%) & & & 0.377 \\
\hline$<1 \mathrm{~h} / \mathrm{d}$ & 0 & 3.6 & \\
\hline $1-2 \mathrm{~h} / \mathrm{d}$ & 15.6 & 14.3 & \\
\hline $2-4 \mathrm{~h} / \mathrm{d}$ & 50.0 & 39.3 & \\
\hline $4-7 \mathrm{~h} / \mathrm{d}$ & 28.1 & 42.9 & \\
\hline$>7 \mathrm{~h} / \mathrm{d}$ & 6.3 & 0 & \\
\hline Milk consumption (\%) & & & 0.306 \\
\hline$<1$ portion/d & 21.9 & 22.2 & \\
\hline 1-2 portion/d & 46.9 & 63.0 & \\
\hline 2-4 portion/d & 31.3 & 14.8 & \\
\hline Smoking habits (\%) & & & 0.179 \\
\hline No & 71.9 & 71.4 & \\
\hline Quit & 15.6 & 3.6 & \\
\hline Yes & 12.5 & 25.0 & \\
\hline Clothing style (\%) & & & 0.727 \\
\hline Western-style clothing & 37.5 & 39.3 & \\
\hline Traditional & 37.5 & 28.6 & \\
\hline Oriental-style clothing & 25.0 & 32.1 & \\
\hline
\end{tabular}

$25-(\mathrm{OH}) \mathrm{D}$ levels greater than $20 \mathrm{ng} / \mathrm{mL}(50 \mathrm{nmol} / \mathrm{L})$ were achieved in $96.7 \%$ of patients in the single large dose group at the end of 4th week, whereas it was $19.4 \%$ of patients in the daily low-dosage group $(p<$ 0.001 ) (Table 4). Serum 25-(OH)D levels greater than $30 \mathrm{ng} / \mathrm{mL}(75 \mathrm{nmol} / \mathrm{L})$ were achieved in $63.3 \%$ of patients in single large dose group at the end of 4th week compared with $3.2 \%$ in the daily low-dosage group $(\mathrm{p}<0.001)$. Serum $25-(\mathrm{OH}) \mathrm{D}$ levels greater than $20 \mathrm{ng} / \mathrm{mL}(50 \mathrm{nmol} / \mathrm{l})$ were achieved in $63.3 \%$ of patients in the single large dose group at the end of 12 th week, whereas it was $45.2 \%$ in the daily low-dosage group $(p>0.05)$. The proportion of patients reaching vitamin $D$ levels of $30 \mathrm{ng} / \mathrm{mL}$
(75 $\mathrm{nmol} / \mathrm{L})$ were similar in both groups $(6.7 \%$ vs. $6.5 \%, \mathrm{p}>0.05)$.

\section{Discussion}

25(OH)D3 levels increased significantly in both groups at weeks 4 and 12 week after vitamin D treatment. The increase in the single-dose group was significantly higher than in the daily low- dosage group at the 4th and 12th week.

In a study, it was demonstrated that a serum 25(OH)D3 level higher than $20 \mathrm{ng} / \mathrm{mL}(50 \mathrm{nmol} / \mathrm{L})$ was achieved with a vitamin $\mathrm{D}(3)$ dosage of $800 \mathrm{IU} / \mathrm{d}$ in $97.5 \%$ of women. Approximately $50 \%$ of patients in the same study group reached vitamin D levels of $30 \mathrm{ng} / \mathrm{mL}$ 
Table 2 The biochemical results of the single-dose and daily-dosage group at pretreatment, 4th, and 12th week

\begin{tabular}{|c|c|c|c|c|c|c|c|c|}
\hline & \multicolumn{4}{|c|}{ Single-dose group } & \multicolumn{4}{|c|}{ Daily-dosage group } \\
\hline & Pretreatment & 4th week & 12th week & $p$ & Pretreatment & 4th week & 12th week & $p$ \\
\hline Glucose (mg/dL) & $88.2 \pm 9.8$ & $81.7 \pm 17.4$ & $92.4 \pm 9.5$ & 0.014 & $89.1 \pm 7.5$ & $85.3 \pm 6.8$ & $88.6 \pm 18.0$ & 0.016 \\
\hline Total cholesterol (mg/dL) & $209.5 \pm 37.4$ & $209.1 \pm 27.0$ & $204.7 \pm 35.4$ & 0.569 & $203.6 \pm 36.6$ & $1999.1 \pm 38.8$ & $212.3 \pm 33.6$ & 0.763 \\
\hline Triglycerides (mg/dL) & $136.5 \pm 49.6$ & $115.6 \pm 43.7$ & $128.7 \pm 56.1$ & 0.108 & $148.5 \pm 72.7$ & $146.6 \pm 90.3$ & $154.6 \pm 61.9$ & 0.601 \\
\hline LDL-cholesterol (mg/dL) & $133.4 \pm 32.3$ & $137.5 \pm 23.7$ & $131.3 \pm 26.7$ & 0.411 & $125.6 \pm 27.8$ & $122.1 \pm 31.1$ & $134.5 \pm 32.2$ & 0.301 \\
\hline \multicolumn{9}{|l|}{ Calcium } \\
\hline$(\mathrm{mg} / \mathrm{dL})$ & $9.5 \pm 0.4$ & $9.5 \pm 0.4$ & $9.4 \pm 0.5$ & 0.507 & $9.4 \pm 0.4$ & $9.5 \pm 0.5$ & $9.6 \pm 0.4$ & 0.059 \\
\hline$(\mathrm{mmol} / \mathrm{L})$ & $2.3 \pm 0.1$ & $2.3 \pm 0.1$ & $2.3 \pm 0.1$ & & $2.3 \pm 0.1$ & $2.3 \pm 0.1$ & $2.4 \pm 0.1$ & \\
\hline Phosphorus (mg/dL) & $3.5 \pm 0.4$ & $3.8 \pm 0.4$ & $3.6 \pm 0.6$ & 0.043 & $3.4 \pm 0.5$ & $3.9 \pm 0.5$ & $3.9 \pm 0.5$ & $<0.001$ \\
\hline Magnesium (mg/dL) & $2.1 \pm 0.2$ & & & & $2.2 \pm 0.2$ & & & \\
\hline iPTH (pg/ml) & $55.1 \pm 24.3$ & $47.7 \pm 19.1$ & $50.7 \pm 20.5$ & 0.152 & $62.4 \pm 24.9$ & $55.9 \pm 22.8$ & $54.9 \pm 20.6$ & 0.081 \\
\hline \multicolumn{9}{|l|}{ Vitamin D } \\
\hline$(\mathrm{ng} / \mathrm{mL})$ & $9.7 \pm 4.4$ & $35.9 \pm 9.6$ & $23.1 \pm 4.7$ & $<0.001$ & $10.2 \pm 4.4$ & $16.9 \pm 5.8$ & $19.8 \pm 7.2$ & $<0.001$ \\
\hline$(\mathrm{nmol} / \mathrm{L})$ & $24.2 \pm 10.9$ & $89.6 \pm 23.9$ & $57.6 \pm 11.7$ & & $25.4 \pm 10.9$ & $42.1 \pm 14.4$ & $49.4 \pm 17.9$ & \\
\hline Osteocalcin (ng/ml) & $21.2 \pm 19.1$ & $21.9 \pm 7.5$ & $20.5 \pm 7.6$ & 0.231 & $11.2 \pm 8.3$ & $22.0 \pm 7.2$ & $20.4 \pm 5.5$ & 0.008 \\
\hline Alkaline phosphatase (units/L) & $72.5 \pm 20.7$ & $73.0 \pm 23.1$ & $73.6 \pm 19.8$ & 0.138 & $69.6 \pm 17.6$ & $68.1 \pm 19.6$ & $68.0 \pm 19.1$ & 0.051 \\
\hline TSH (mIU/L) & $2.5 \pm 1.5$ & $2.8 \pm 2.0$ & $2.4 \pm 1.5$ & 0.580 & $2.2 \pm 1.1$ & $2.2 \pm 1.3$ & $2.2 \pm 1.4$ & 0.965 \\
\hline hs-CRP (mg/L) & $3.3 \pm 3.1$ & $3.2 \pm 3.2$ & $2.4 \pm 2.2$ & 0.188 & $4.5 \pm 4.9$ & $4.1 \pm 3.7$ & $4.1 \pm 3.9$ & 0.376 \\
\hline
\end{tabular}

(75 $\mathrm{nmol} / \mathrm{L})$ [11]. In the present study, $45.2 \%$ of patients reached serum 25(OH)D3 levels of more than $20 \mathrm{ng} / \mathrm{mL}$ $(50 \mathrm{nmol} / \mathrm{L})$ with daily $800 \mathrm{IU}$ vitamin $\mathrm{D}$ replacement dosages, whereas only $6.5 \%$ of patients reached serum 25(OH)D3 levels higher than $30 \mathrm{ng} / \mathrm{mL}$ (75 nmol/L). This difference may be partly explained by the difference between baseline vitamin $\mathrm{D}$ levels in both studies $(10.2 \mathrm{ng} / \mathrm{mL}(25.4 \mathrm{nmol} / \mathrm{L})$ vs. $15.6 \mathrm{ng} / \mathrm{mL}(38.6 \mathrm{nmol} / \mathrm{L}))$.

Vitamin D levels significantly increased at the 4th week when compared with baseline in a study conducted with single high dose of vitamin D (300,000 IU); however, vitamin D levels at the 12 th week were similar at baseline [4]. A recent study demonstrated that a single dose of 250,000 IU of vitamin D3 concluded in a robust increase in plasma $25(\mathrm{OH}) \mathrm{D} 3$ after 5 days, but it decreased to baseline levels after 90 days. The authors proposed that a larger dose or more frequent dosing regimen might be required for long-term management of vitamin D insufficiency [27]. In our study, vitamin D levels increased significantly in the single high-dose group at the 4th and 12th weeks after vitamin D3 treatment; however, vitamin D levels decreased at the 12th week when compared with the 4th week in the single large-dose group. Maintenance doses with regular intervals would be reasonable in patients undergoing single large-dose vitamin D replacement.

Human skeletal muscles express vitamin D receptors (VDR) and genotypic variations for this receptor have been reported to be related to decreased muscle strength. It is known that vitamin D has an important role in muscle strength and function. This condition is more prominent in proximal muscles of lower extremity. Because of this, we evaluated knee muscles strength such as quadriceps and hamstrings. It is difficult to evaluate the hip muscles strengh with isokinetic device, therefore we selected the knee muscles [28]. Moreover, vitamin D deficiency-associated muscle weakness is predominantly of the proximal muscle groups and has an effect on daily living activities including walking and climbing stairs [10].

Table 3 Relative isokinetic peak torques $(\mathrm{Nm} / \mathrm{kg})$ of the knee extensor and flexor muscles

\begin{tabular}{|c|c|c|c|c|c|c|c|c|c|c|}
\hline & \multicolumn{5}{|c|}{ Knee extension } & \multicolumn{5}{|c|}{ Knee flexion } \\
\hline & \multicolumn{2}{|c|}{ Daily-dosage group } & \multicolumn{2}{|c|}{ Single-dose group } & \multirow[t]{2}{*}{$p$-value ${ }^{a}$} & \multicolumn{2}{|c|}{ Daily -dosage group } & \multicolumn{2}{|c|}{ Single-dose group } & \multirow[t]{2}{*}{$\overline{p \text {-value }}$} \\
\hline & Dominant & Non-dominant & Dominant & Non-dominant & & Dominant & Non-dominant & Dominant & Non-dominant & \\
\hline Pretreatment & $0.97 \pm 0.4$ & $0.98 \pm 0.4$ & $1.02 \pm 0.3$ & $0.99 \pm 0.4$ & $0.62 / 0.89$ & $0.34 \pm 0.1$ & $0.32 \pm 0.1$ & $0.36 \pm 0.2$ & $0.33 \pm 0.2$ & $0.62 / 0.81$ \\
\hline 4th week & $1.06 \pm 0.4$ & $1.09 \pm 0.4$ & $1.05 \pm 0.3$ & $1.06 \pm 0.3$ & $0.95 / 0.78$ & $0.37 \pm 0.2$ & $0.36 \pm 0.2$ & $0.39 \pm 0.2$ & $0.39 \pm 0.2$ & $0.69 / 0.59$ \\
\hline 12th week & $1.03 \pm 0.3$ & $1.05 \pm 0.4$ & $1.13 \pm 0.3$ & $1.14 \pm 0.3$ & $0.35 / 0.36$ & $0.37 \pm 0.1$ & $0.37 \pm 0.1$ & $0.39 \pm 0.2$ & $0.40 \pm 0.2$ & $0.69 / 0.55$ \\
\hline$p$ value & $0.03^{b}$ & 0.21 & 0.20 & 0.05 & & 0.18 & $0.03^{c}$ & 0.22 & 0.10 & \\
\hline
\end{tabular}


Table 4 Percentage of patients that reach target serum $25 \mathrm{OH}$ vitamin level based on treatment duration and replacement style

\begin{tabular}{lll}
\hline & Daily dose group & Single dose group \\
\hline 4th week Vitamin $D<20$ & $23(\% 74.2)$ & $0(\% 0)$ \\
Vitamin $D \geq 20$ & $6(\% 19.4)$ & $29(\% 96.7)$ \\
4th week Vitamin $D<30$ & $28(\% 90.3)$ & $10(33.3 \%)$ \\
Vitamin $D \geq 30$ & $1(\% 3.2)$ & $19(63.3 \%)$ \\
1 th week Vitamin $D<20$ & $12(38.7 \%)$ & $8(26.7 \%)$ \\
Vitamin $D \geq 20$ & $14(45,2 \%)$ & $19(63.3 \%)$ \\
12th week Vitamin $D<30$ & $24(77.4 \%)$ & $25(83.3 \%)$ \\
Vitamin $D \geq 30$ & $2(6.5 \%)$ & $2(6.7 \%)$ \\
\hline
\end{tabular}

Marantes et al. observed no consistent association between 25(OH)D3 levels and any measurements related to muscle mass or strength in either men or women. The authors proposed that factors affecting neuromuscular function rather than muscle strength might be responsible for the association between low 25(OH)D3 and increased fall risk observed in other studies [29]. Several studies evaluated lower leg isometric muscle strength $[16,19,23,30-34]$; however, only two demonstrated an improvement in isometric muscle strength after treatment [19, 31]. Pfeifer et al. found significantly increased quadriceps strength after 6 months of treatment with 800 IU/ day vitamin D3 [33]. Similarly, Moreira-Pfrimer et al. demonstrated an improvement in maximal isometric strength of hip flexors and knee extensors in vitamin D3-treated subjects $(150,000$ IU once a month during the first 2 months, followed by 90,000 IU once a month for the last 4 months) [19]. Handgrip strength after vitamin D replacement was evaluated in five studies, and none was able to show significant effects $[23,30,32,35,36]$. A recent meta-analysis reported muscle strength measures of 29 randomized controlled trials involving 5533 subjects [37]. The results demonstrated that vitamin D replacement had a small, but significantly positive impact on global muscle strength. A significant positive effect on lower limb muscle strength was observed, but handgrip muscle strength was not affected. Supplementation seemed to be more effective in patients who presented with a 25(OH)D3 levels $<12 \mathrm{ng} / \mathrm{mL}(30 \mathrm{nmol} / \mathrm{L})$ and aged 65 years or over. The authors proposed that these results could explain the significant effect of vitamin D on falls determined in meta-analyses [38, 39]. Indeed, quadriceps strength was determined to be a significant predictor of fall incidence [40]. We found a significant improvement in dominant quadriceps and non-dominant hamstring muscle strengths in the daily vitamin D group. Non-dominant quadriceps and dominant hamstring muscle strengths were also increased but the differences were not statistically significant. The sample size of our study was not large enough to detect a significant difference. The differences in dose of oral vitamin $\mathrm{D}$, patient population, treatment interval, and muscle strength assessment test have been considered to be responsible for the inconsistencies.

In our study, both replacement types were found to be safe but vitamin D levels were demonstrated to be higher after replacement with single large doses. However, the effect of daily low-dosage vitamin D replacement on muscle strength was better than single large-dose replacement. These findings might support the results of a randomized controlled trial which demonstrated high-dose colecalciferol leads to a higher risk of falls and fractures in older community-dwelling women [41]. Long-term studies with larger populations investigating skeletal development, bone health maintenance, and non-skeletal effects of vitamin $\mathrm{D}$ are required to clarify the best replacement dose and form for adequate vitamin $\mathrm{D}$ levels in the maintenance of health.

Being a single center stduy and a relatively small sample size were the limitations of the study. Being at lower threshold levels of vitamin $\mathrm{D}_{3}$ which known to decrease fracture risk and falls at 1st and 3th of months of study could be another limitation of the study (referans), as it may make difficult to interpret the results of the study. Additionally, none of our patients was evaluated for vitamin D metabolites which has been demonstrated to be related to muscle function in recent studies. This is another limitation of our study.

\section{Conclusion}

Although daily administration routes are more effective in improving muscle strength, a single administration is more effective in increasing vitamin D levels.

\begin{abstract}
Abbreviations
BMI: body mass index; CD: Celiac disease; DBP: diastolic blood pressure; EMA: anti endomysium antibody; ERS: endoplasmic reticulum stress; FPG: fasting plasma glucose; HC: hip circumference; HLD-C: HDL cholesterol; LDL-C: LDL-cholesterol; NIDDM: non-insulin dependent diabetes mellitus; PPPG: post-prandial plasma glucose; SBP: systolic blood pressure; T2DM: type 2 diabetes mellitus; TLR: Tool-like receptors; tTGA IgA: tissue transglutaminase antibody IgA; VA: villous atrophy; WC: waist circumference
\end{abstract}

Availability of data and materials

The datasets used and/or analyzed during the current study available from the corresponding author on reasonable request. 


\section{Authors' contributions}

MA: have made contributions to conception and design, acquisition of data, and analysis and interpretation of data. AGC, MK, SB: have made contributions to acquisition of data and interpretation of data. SK, MC, TD, OO: have made contributions to acquisition of data. MK, SB: performed the statistical analysis. MO, EC: have made contributions to conception, design, and interpretation of data. All authors read and approved the final manuscript.

\section{Ethics approval and consent to participate}

Approval of ethical committee and written informed consent of participants were obtained before the study (Diskapi Training and Research Hospital. Date: 26. 01. 2015, Reference No:19/36).

\section{Consent for publication}

Non applicable.

\section{Competing interests}

The authors declare that they have no competing interest.

\section{Publisher's Note}

Springer Nature remains neutral with regard to jurisdictional claims in published maps and institutional affiliations.

\section{Author details}

'Department of Endocrinology and Metabolism, Diskapi Training and Research Hospital, Ankara, Turkey. ${ }^{2}$ Department of Physical Medicine and Rehabilitation, Diskapi Training and Research Hospital, Ankara, Turkey.

Received: 17 January 2018 Accepted: 11 July 2018

Published online: 21 July 2018

\section{References}

1. Plum LA, DeLuca HF. Vitamin D, disease and therapeutic opportunities. Nat Rev Drug Discov. 2010:9(12):941-55.

2. Bordelon P, Ghetu MV, Langan RC. Recognition and management of vitamin D deficiency. Am Fam Physician. 2009:80(8):841-6.

3. Holick MF, Chen TC. Vitamin D deficiency: a worldwide problem with health consequences. Am J Clin Nutr. 2008:87(4):1080S-6S.

4. Rossini $M$, et al. Dose-dependent short-term effects of single high doses of oral vitamin D(3) on bone turnover markers. Calcif Tissue Int. 2012:91(6):365-9.

5. Holick MF, et al. Evaluation, treatment, and prevention of vitamin D deficiency: an Endocrine Society clinical practice guideline. J Clin Endocrino Metab. 2011;96(7):1911-30

6. Holick MF. Optimal vitamin D status for the prevention and treatment of osteoporosis. Drugs Aging. 2007;24(12):1017-29.

7. Bischoff, H.A., et al., In situ detection of 1,25-dihydroxyvitamin D3 receptor in human skeletal muscle tissue. Histochem J, 2001. 33(1): p. 19-24.

8. Marcinkowska E. A run for a membrane vitamin D receptor. Biol Signals Recept. 2001;10(6):341-9.

9. Rinaldi l, et al. Correlation between serum vitamin D $(25(\mathrm{OH}) \mathrm{D})$ concentration and quadriceps femoris muscle strength in Indonesian elderly women living in three nursing homes. Acta Med Indones. 2007:39(3):107-11.

10. Ceglia L. Vitamin D and skeletal muscle tissue and function. Mol Asp Med. 2008;29(6):407-14

11. Gallagher JC, et al. Dose response to vitamin D supplementation in postmenopausal women: a randomized trial. Ann Intern Med. 2012;156(6):425-37.

12. Trivedi DP, Doll $R$, Khaw KT. Effect of four monthly oral vitamin D3 (colecalciferol) supplementation on fractures and mortality in men and women living in the community: randomised double blind controlled trial. BMJ. 2003;326(7387):469.

13. Sanfelix-Genoves J, et al. Determinant factors of osteoporosis patients' reported therapeutic adherence to calcium and/or vitamin D supplements: a cross-sectional, observational study of postmenopausal women. Drugs Aging. 2009;26(10):861-9.

14. Diez A, et al. Observational study of treatment compliance in women initiating antiresorptive therapy with or without calcium and vitamin D supplements in Spain. Menopause. 2012;19(1):89-95.
15. Diamond $\mathrm{TH}$, et al. Annual intramuscular injection of a megadose of colecalciferol for treatment of vitamin D deficiency: efficacy and safety data. Med J Aust. 2005;183(1):10-2.

16. Dhesi JK, et al. Vitamin D supplementation improves neuromuscular function in older people who fall. Age Ageing. 2004;33(6):589-95.

17. Leventis P, Kiely PD. The tolerability and biochemical effects of high-dose bolus vitamin D2 and D3 supplementation in patients with vitamin D insufficiency. Scand J Rheumatol. 2009;38(2):149-53.

18. Ilahi M, Armas LA, Heaney RP. Pharmacokinetics of a single, large dose of colecalciferol. Am J Clin Nutr. 2008;87(3):688-91.

19. Moreira-Pfrimer $L D$, et al. Treatment of vitamin $D$ deficiency increases lower limb muscle strength in institutionalized older people independently of regular physical activity: a randomized double-blind controlled trial. Ann Nutr Metab. 2009;54(4):291-300.

20. Kearns MD, Alvarez JA, Tangpricha V. Large, single-dose, oral vitamin d supplementation in adult populations: a systematic review. Endocr Pract 2014:20(4):341-51

21. Janssen HC, Samson MM, Verhaar HJ. Vitamin D deficiency, muscle function, and falls in elderly people. Am J Clin Nutr. 2002;75(4):611-5.

22. Schacht E, Ringe JD. Alfacalcidol improves muscle power, muscle function and balance in elderly patients with reduced bone mass. Rheumatol Int. 2012;32(1):207-15.

23. Kenny AM, et al. Effects of vitamin D supplementation on strength, physical function, and health perception in older, community-dwelling men. Am Geriatr Soc. 2003;51(12):1762-7.

24. Grady, D., et al., 1,25-Dihydroxyvitamin D3 and muscle strength in the elderly: a randomized controlled trial. J Clin Endocrinol Metab, 1991. 73(5): p. 1111-7.

25. Muir SW, Montero-Odasso M. Effect of vitamin D supplementation on muscle strength, gait and balance in older adults: a systematic review and meta-analysis. J Am Geriatr Soc. 2011;59(12):2291-300.

26. Stockton KA, et al. Effect of vitamin D supplementation on muscle strength: a systematic review and meta-analysis. Osteoporos Int. 2011;22(3):859-71.

27. Kearns MD, et al. The effect of a single, large bolus of vitamin $D$ in healthy adults over the winter and following year: a randomized, double-blind, placebo-controlled trial. Eur J Clin Nutr. 2015;69(2):193-7.

28. Rejnmark $L$. Effects of vitamin D on muscle function and performance: a review of evidence from randomized controlled trials. Ther Adv Chronic Dis, 2011;2:25-37

29. Marantes I, et al. Is vitamin D a determinant of muscle mass and strength? J Bone Miner Res. 2011;26(12):2860-71.

30. Janssen HC, Samson MM, Verhaar HJ. Muscle strength and mobility in vitamin D-insufficient female geriatric patients: a randomized controlled trial on vitamin D and calcium supplementation. Aging Clin Exp Res. 2010;22(1):78-84.

31. Pfeifer $M$, et al. Effects of a long-term vitamin $D$ and calcium supplementation on falls and parameters of muscle function in communitydwelling older individuals. Osteoporos Int. 2009;20(2):315-22.

32. Bunout $D$, et al. Effects of vitamin $D$ supplementation and exercise training on physical performance in Chilean vitamin $D$ deficient elderly subjects. Exp Gerontol. 2006:41(8):746-52.

33. Bischoff HA, et al. Effects of vitamin D and calcium supplementation on falls: a randomized controlled trial. J Bone Miner Res. 2003:18(2):343-51.

34. Latham NK, et al. A randomized, controlled trial of quadriceps resistance exercise and vitamin D in frail older people: the frailty interventions trial in elderly subjects (FITNESS). J Am Geriatr Soc. 2003;51(3):291-9.

35. Brunner RL, et al. Calcium, vitamin D supplementation, and physical function in the Women's Health Initiative. J Am Diet Assoc. 2008;108(9):1472-9.

36. El-Hajj Fuleihan $\mathrm{G}$, et al. Effect of vitamin D replacement on musculoskeletal parameters in school children: a randomized controlled trial. J Clin Endocrinol Metab. 2006:91(2):405-12.

37. Beaudart $C$, et al. The effects of vitamin $D$ on skeletal muscle strength, muscle mass, and muscle power: a systematic review and meta-analysis of randomized controlled trials. J Clin Endocrinol Metab. 2014;99(11):4336-45.

38. Kalyani RR, et al. Vitamin D treatment for the prevention of falls in older adults: systematic review and meta-analysis. J Am Geriatr Soc. 2010:58(7):1299-310.

39. Murad MH, et al. Clinical review: the effect of vitamin D on falls: a systematic review and meta-analysis. J Clin Endocrinol Metab. 2011;96(10):2997-3006 
40. Scott $D$, et al. Investigating the predictive ability of gait speed and quadriceps strength for incident falls in community-dwelling older women at high risk of fracture. Arch Gerontol Geriatr. 2014;58(3):308-13.

41. Sanders KM, Stuart AL, Williamson EJ, Simpson JA, Kotowicz MA, Young D, et al. Annual high-dose oral vitamin $D$ and falls and fractures in older women: a randomized controlled trial. JAMA. 2010;303(18):1815-22.

Ready to submit your research? Choose BMC and benefit from:

- fast, convenient online submission

- thorough peer review by experienced researchers in your field

- rapid publication on acceptance

- support for research data, including large and complex data types

- gold Open Access which fosters wider collaboration and increased citations

- maximum visibility for your research: over $100 \mathrm{M}$ website views per year

At $\mathrm{BMC}$, research is always in progress.

Learn more biomedcentral.com/submissions 